\title{
Sofosbuvir for the treatment of hepatitis $C$ virus infection
}

\author{
Sébastien Rolland BPharm MD, Marie-Louise Vachon MD MSc
}

A bout $2 \%-3 \%$ of the world's population is infected with hepatitis $\mathrm{C}$ virus (HCV), with an estimated prevalence of $0.8 \%$ in Canada or more than 240000 Canadians infected. ${ }^{1}$ Of the six HCV genotypes, genotype 1 is the most prevalent in Canada. Despite therapeutic advances afforded by the NS3/4A protease inhibitors telaprevir and boceprevir for the treatment of HCV genotype 1 infection since 2011, about 25\%-35\% of treatment-naive patients do not achieve a sustained virologic response even with up to 48 weeks of treatment. ${ }^{2,3}$ Furthermore, telaprevir and boceprevir are associated with a high pill burden, food requirements, drug interactions and numerous adverse effects, including severe anemia and rash. Both have to be taken in combination with peginterferon and ribavirin. Interferon can cause substantial adverse effects such as influenza-like symptoms, fatigue and depression.

For HCV genotype 2 or 3 infection, peginterferon-ribavirin combination therapy leads to sustained virologic response rates between $60 \%$ and $80 \%$ with 24 weeks of treatment. ${ }^{4}$ Until recently, patients with HCV genotype 2 or 3 infection who did not achieve a sustained virologic response or who had contraindications to peginterferon-ribavirin were left with no therapeutic options.

\section{What is sofosbuvir?}

Sofosbuvir is a first-in-class nucleotide inhibitor of the nonstructural protein $5 \mathrm{~B}$ (NS5B, the HCV RNA-dependent RNA polymerase) that was approved by Health Canada in December 2013. Nucleotide inhibitors such as sofosbuvir are phosphorylated to the active form (the nucleoside triphosphate), which competes with the natural substrate leading to chain termination during RNA replication. Sofosbuvir has a high barrier to resistance, pan-genotypic activity and once-daily dosing. This directacting antiviral agent can be used without peginterferon.

\section{How is sofosbuvir delivered?}

Sofosbuvir is administered as a tablet once daily with or without food. Dosage adjustment is unnecessary in patients with mild to moderate renal impairment. The medication is given with peginterferon-ribavirin for $\mathrm{HCV}$ genotype 1, 4, 5 or 6 infection. It is given with ribavirin for $\mathrm{HCV}$ genotype 2 or 3 infection.

\section{Who is eligible?}

Patients with HCV genotype 1-6 infection are eligible for sofosbuvir treatment. The drug is approved by Health Canada for HCV genotype 1-4 infection, including for patients with compensated cirrhosis, but not for HCV genotype 5 or 6 infection. Although patients with $\mathrm{HCV}$ genotype 5 or 6 infection were included in the NEUTRINO trial (a phase III, single-group, open-label trial) and had high sustained virologic response rates, only seven participated in the trial. ${ }^{5}$

\section{What are the possible harms?}

In the randomized double-blind placebo-controlled POSITRON trial, the rates of serious adverse events were $5 \%$ in the sofosbuvir-ribavirin group and $3 \%$ in the placebo group. ${ }^{6}$ The difference in rates was due to fatigue, insomnia and anemia occurring more frequently in the treatment group than in the placebo group. ${ }^{6}$ The increased incidence of anemia is an expected adverse event associated with ribavirin use and led to discontinuation of treatment in one patient in the active-treatment group $(0.5 \%$ v. $0 \%)$.

\author{
Competing interests: \\ Marie-Louise Vachon has \\ received consulting fees \\ from Boehringer \\ Ingelheim and Merck; \\ consulting fees and lecture \\ honoraria from Janssen \\ Pharmaceuticals, Gilead, \\ Hoffman-La Roche and \\ Vertex Pharmaceuticals; \\ and speaker fees from \\ Gilead. No competing \\ interests were declared by \\ Sébastien Rolland.
}

This article has been peer reviewed.

Correspondence to: Marie-Louise Vachon, Marie-Louise.Vachon @mail.chuq.qc.ca

CMAJ 2015. DOI:10.1503 /cmaj.140151

\section{KEY POINTS}

- The data pertaining to sofosbuvir support its use as part of combination therapy in the treatment of chronic HCV infection.

- Sofosbuvir combined with ribavirin provides an interferon-free treatment regimen for HCV genotype 2 or 3 infection, which will likely enhance patient adherence and treatment acceptance.

- For HCV genotype 1 or 4 infection, sofosbuvir plus peginterferon-ribavirin is given for 12 weeks, constituting an interferon-limiting option.

- Sofosbuvir was approved by the US Food and Drug Administration and Health Canada in December 2013. 


\section{What is the evidence so far?}

Results of published phase III trials of sofosbuvir in combination with ribavirin or peginterferon-ribavirin are summarized in Appendix 1 (available at www.cmaj.ca/lookup/suppl /doi:10.1503/cmaj.140151/-/DC1). In the NEUTRINO trial, ${ }^{5} 327$ treatment-naive patients with HCV infection received sofosbuvir plus peginterferon-ribavirin for 12 weeks. Most (89\%) had HCV genotype 1 infection, and the remainder had HCV genotype 4, 5 or 6 infection. The sustained virologic response rate at 12 weeks was $90 \%$. Among patients with cirrhosis, the sustained virologic response rate was $80 \%$, which is the highest rate reported in that population.

Sofosbuvir in combination with ribavirin was investigated in treatment-naive patients with HCV genotype 2 or 3 infection in the FISSION trial, an open-label randomized active-control trial. $^{5}$ A sustained virologic response rate of $67 \%$ at 12 weeks was observed in both the sofosbuvir-ribavirin and the peginterferonribavirin arms. In the POSITRON trial, ${ }^{6}$ patients with $\mathrm{HCV}$ genotype 2 or 3 infection who were intolerant of or ineligible for interferon treatment were randomly assigned to either the sofosbuvir-ribavirin arm or the matching placebo arm. The sustained virologic response rate at 12 weeks was $78 \%$ in the intervention group and $0 \%$ in the placebo group.

In the randomized double-blind FUSION trial, ${ }^{6}$ treatment-experienced patients with $\mathrm{HCV}$ genotype 2 or 3 infection received either 12 or 16 weeks of sofosbuvir plus ribavirin. For patients with $\mathrm{HCV}$ genotype 3 infection, extending the duration of treatment from 12 to 16 weeks enhanced the sustained virologic response rates substantially, from $19 \%$ to $60 \%$ in patients with cirrhosis. The VALENCE trial provided the basis for an option to lengthen treatment duration to 24 weeks in patients with $\mathrm{HCV}$ genotype 3 infection. ${ }^{7}$

Sofosbuvir is characterized by a high barrier to resistance. The S282T mutation is the only NS5B polymerase mutation detected that confers reduced susceptibility to sofosbuvir and has been found in two patients at the time of relapse. ${ }^{8,9}$ Patient compliance will likely be the key to avoiding resistance. Results of phase II and III trials combining sofosbuvir with other direct-acting antiviral agents, such as simeprevir (protease inhibitor), ${ }^{10}$ daclatasvir (NS5A inhibitor) ${ }^{11}$ or ledipasvir (NS5A inhibitor), ${ }^{12-14}$ have promise as future peginterferon- and ribavirin-free options in patients with $\mathrm{HCV}$ infection.

\section{What can we expect in the future?}

The data pertaining to sofosbuvir support its use as part of combination therapy in the treatment of chronic HCV genotype 1-4 infection. Whether combined with ribavirin alone, with peginterferon and ribavirin, or with other direct-acting antiviral agents, sofosbuvir will likely have a large impact on the treatment of HCV infection. Studies assessing the safety and efficacy of sofosbuvir in traditionally difficult-to-treat populations (e.g., patients receiving liver transplantation or hemodialysis, people with hemophilia and those with $\mathrm{HIV} / \mathrm{HCV}$ co-infection) are currently underway. Combinations of sofosbuvir with other direct-acting antiviral agents are also being evaluated. ${ }^{11-14}$ Other promising interferon-free combinations that do not involve sofosbuvir are also in development.

\section{References}

1. Hepatitis C in Canada: 2005-2010 surveillance report. Ottawa (ON): Public Health Agency of Canada; 2012. Available: www.phac-aspc.gc.ca/sti-its-surv-epi/hepc/surv-eng.php (accessed 2013 Sept. 6).

2. Jacobson IM, McHutchison JG, Dusheiko G, et al. Telaprevir for previously untreated chronic hepatitis $\mathrm{C}$ virus infection. $N$ Engl $J$ Med 2011;364:2405-16.

3. Poordad F, McCone J, Bacon BR, et al. Boceprevir for untreated chronic HCV genotype 1 infection. N Engl J Med 2011;364: 1195-206.

4. Shiffman ML, Suter F, Bacon BR, et al. Peginterferon alfa-2a and ribavirin for 16 or 24 weeks in HCV genotype 2 or 3. N Engl J Med 2007;357:124-34.

5. Lawitz E, Mangia A, Wyles D, et al. Sofosbuvir for previously untreated chronic hepatitis C infection. N Engl J Med 2013;368:1878-87.

6. Jacobson IM, Gordon SC, Kowdley KV, et al. Sofosbuvir for hepatitis $\mathrm{C}$ genotype 2 or 3 in patients without treatment options. N Engl J Med 2013;368:1867-77.

7. Zeuzem S, Dusheiko GM, Salupere R, et al. Sofosbuvir and ribavirin in HCV genotype 2 or 3. N Engl J Med 2014;370:1993.

8. Gane EJ, Stedman CA, Hyland RH, et al. Nucleotide polymerase inhibitor sofosbuvir plus ribavirin for hepatitis C. N Engl J Med 2013;368:34-44.

9. Lawitz E, Poordad FF, Pang PS, et al. Sofosbuvir and ledipasvir fixed-dose combination with and without ribavirin in treatmentnaive and previously treated patients with genotype 1 hepatitis $\mathrm{C}$ virus infection (LONESTAR): an open-label, randomised, phase 2 trial. Lancet 2014;383:515-23.

10. Sulkowski MS, Jacobson IM, Ghalib R, et al. Once-daily simeprevir (TMC435) plus sofosbuvir (GS-7977) with or without ribavirin in $\mathrm{HCV}$ genotype 1 prior null responders with METAVIR F0-2: COSMOS study subgroup analysis. J Hepatol 2014;60(Suppl):S4.

11. Sulkowski MS, Gardiner DF, Rodriguez-Torres M, et al. Daclastavir plus sofosbuvir for previously treated or untreated chronic HCV infection. N Engl J Med 2014;370:211-21.

12. Afdhal N, Zeuzum S, Kwo P, et al. Ledipasvir and sofosbuvir for untreated HCV genotype 1 infection. N Engl J Med 2014;370:1889.

13. Afdhal N, Reddy KR, Nelson DR, et al. Ledipasvir and sofosbuvir for previously treated HCV genotype 1 infection. $N$ Engl $J$ Med 2014;370:1483.

14. Kowdley KV, Gordon SC, Reddy KR, et al. Ledipasvir and sofosbuvir for 8 or 12 weeks for chronic HCV without cirrhosis. N Engl J Med 2014;370:1879.

Affiliations: Department of Medicine (Rolland), Division of Infectious Diseases (Vachon), Université Laval, Québec City, Que.

Contributors: Sébastien Rolland drafted the manuscript. Both authors revised the manuscript for important intellectual content, approved the final version submitted for publication and agreed to act as guarantors of the work. 